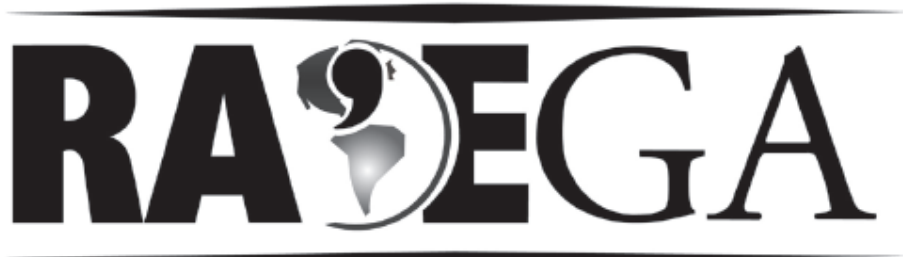

O ESPAÇO GEOGRÁFICO EM ANÁLISE

\title{
GEOTECNOLOGIAS APLICADAS AO ESTUDO DE FORMAÇÃO E DE RISCO AMBIENTAL DAS FAVELAS DE MONTES CLAROS/MG
}

\section{GEOTECHNOLOGIES APPLIED TO THE STUDY OF TRAINING AND ENVIRONMENTAL RISK FROM THE SLUMS OF MONTES CLAROS/MG}

\author{
Marcos Esdras $^{1}$
}

\begin{abstract}
RESUMO
A formação de favelas não é um problema social presente apenas nas grandes cidades. A cidade média brasileira se destaca entre as áreas urbanas com maior número de assentamentos urbanos ilegais, como a favela. Diante do contexto de crescimento demográfico dessas cidades que desde a década de 1990 apresenta um crescimento demográfico maior que as metrópoles há uma perspectiva pessimista que o déficit habitacional nessas cidades tende a aumentar e, consequentemente, surgirão novas favelas. Por isso, é importante contar com instrumentos geotecnológicos que permitam monitorar o espaço urbano de maneira rápida para subsidiar eficazmente a gestão da cidade. Nesse sentido este artigo teve como objetivo entender o processo de formação das favelas de Montes Claros. Além disso, de forma específica analisou as características socioambientais desses assentamentos urbanos, no intuito de identificar os riscos ambientais comuns nas favelas de Montes Claros. Para atingir esses objetivos foi fundamental o uso do sensoriamento remoto, através de imagens de satélites de alta resolução espacial, e o Sistema de Informação Geográfica - SIG.
\end{abstract}

Palavras-Chave: Geotecnologias; Sensoriamento Remoto; SIG; Cidade e Favela.

\footnotetext{
${ }^{1}$ Doutor em Geografia/ Universidade Federal de Uberlândia. Professor do Departamento de Geociências da Universidade Estadual de Montes Claros/UNIMONTES, Cidade: Montes Claros/MG email: marcosesdras@ig.com.br
} 


\section{ABSTRACT}

The formation of slums is not this a social problem only in big cities. The medium sized brazilian towns stands out among urban areas with the highest number of illegal urban settlements such as slums. Considering all the demographic growth of these cities since the 1990s shows a population growth higher than the metropolitan areas there is a pessimistic outlook that the housing deficit in those cities tend to increase and hence there will be new slums. It is therefore important to have tools that allow monitoring geo urban space quickly to support effective management of the city. In that sense, this paper aims to understand the process of formation of slums in Montes Claros. Furthermore, specifically examined the socio-environmental characteristics of these urban settlements in order to identify environmental risks common in the slums of Montes Claros city. To achieve these goals was critical the use of remote sensing through satellite imagery of high spatial resolution, and the Geographic Information System - GIS.

Keywords: Geotechnology; Remote Sensing; GIS; City and Slum.

\section{Introdução}

As favelas estão presentes nas cidades dos países pobres, independente do seu tamanho demográfico, por isso se destacam como um dos principais problemas habitacionais urbanos. O grande desafio para os governos no século XXI é oferecer moradia formal para a população de baixa renda, isso porque os dados da ONU mostram que o número de pessoas morando em assentamentos precários está aumentando. Essa constatação foi publicada no 5ำ Fórum Urbano Mundial realizado na cidade do Rio de Janeiro, em 2010, organizado pela ONU-HABITAT. Esse evento teve como tema "O Direito à Cidade: Unindo o Urbano Dividido". Isso mostra a preocupação da ONU e dos governos nacionais em pensar soluções para o problema da moradia urbana.

Organismos internacionais, como a Organizações das Nações Unidas, através do Programa de Assentamentos Humanos (UN-HABITAT), têm se empenhado em estudar as favelas no mundo. A partir desses estudos surgiram propostas para melhorar a condição de vida da população das favelas nos países pobres. Embora haja esse empenho em melhorar a situação da habitação nas cidades, esse órgão é claro ao afirmar que a maneira de evitar essa situação é a medida preventiva por parte dos gestores públicos. A medida preventiva deve acontecer para impedir que ocupações ilegais ocorram 
principalmente em áreas de risco, pois pode haver tragédias como deslizamento de encostas, enchentes e incêndios, provocando perdas materiais e mortes. Mesmo depois de ocupadas, as favelas devem ser monitoradas com frequência para evitar a sua expansão e prever possíveis desastres.

Nesse contexto de gestão de favela, o sensoriamento remoto e o SIG são instrumentos importantes no ordenamento desse território. As contribuições dessas tecnologias vão desde atividades simples, como a identificação de favelas, até o uso da inteligência artificial para criar cenários futuros, mostrando a expansão das áreas de ocupação ilegal. Para mapear o espaço da favela, a técnica de execução dessa atividade é relativamente simples, pois se usam comandos básicos das geotecnologias. Contudo, as informações obtidas constituem elemento importante para se pensar esse problema, posto que a identificação do que é favela não é uma tarefa simples.

Diante das contribuições do sensoriamento remoto e do SIG no estudo de favelas, este trabalho foi desenvolvido com o objetivo de entender 0 processo de formação e de distribuição das favelas da cidade de Montes Claros. De maneira específica este artigo, também, caracterizou as áreas de favelas de acordo com a hipsometria e a declividade, apontando assim, variáveis importantes para se verificar favelas em área de risco ambiental.

A identificação e o diagnóstico das favelas é uma etapa importante para definir políticas públicas eficazes para os assentamentos urbanos precários, de maneira que os resultados desse trabalho trouxeram dados relevantes para entender as favelas da cidade de Montes Claros.

\section{Referencial teórico}

De maneira geral, a favela se caracteriza como ocupação ilegal do solo urbano para fins de moradia por população de baixa renda. Além disso, Grostein (2002) caracteriza a favela por ocupar terra pública ou particular, com barracos, frequentemente em áreas não requisitadas pelo mercado imobiliário. Corroborando com essa afirmação, Santos (1981) lista algumas características comuns às favelas brasileiras e destaca a sua formação em terrenos de pouco 
valor, impróprios para a construção e localizados em áreas periféricas longe do centro de aglomeração. Por esses atributos, esse autor denomina a favela como habitat clandestino que se instala em terrenos públicos ou abandonados.

Dentre as características das favelas, Souza (2003, p.173) aponta o "status jurídico ilegal, na qualidade de ocupação de terras públicas ou privadas", como ponto característico e marcante das favelas. E argumenta que a pobreza de sua população é, sem dúvida, uma característica distintiva muito comum, mas o nível de pobreza é bastante variável não só entre favelas, mas também no interior de favelas grandes e consolidadas, especialmente quando situadas em áreas valorizadas. A carência de infraestrutura, assim como a pobreza, é, igualmente, uma característica muito comum, mas não menos que a pobreza, variável. A esses critérios se poderia acrescentar a malha viária totalmente irregular.

Santos (1981) ressalta que, geralmente, os habitantes que buscam moradias nas favelas são imigrantes, o que torna, na visão desse autor, a favela um ponto de concentração na cidade de imigrantes recentes. Partindo da ideia que a intensa imigração de população de baixa renda contribui para a formação de favela, as cidades médias reúnem elementos que potencializam a formação de favela. Nessas cidades, o crescimento populacional é acima da média nacional e das metrópoles, além disso, essas cidades, em alguns casos, são polos regionais e destacam-se na oferta de emprego. Essa fusão de elementos atrativos faz com que a população de baixa renda se desloque para o polo regional, isto é, a cidade média.

Esse contexto regional associado à carência de políticas socioeconômicas para gestão do uso do solo e ordenamento do crescimento da cidade torna essa cidade média um cenário propício à formação de novas favelas e expansão das existentes. Com isso, o uso de instrumentos tecnológicos para monitoramento do uso do solo urbano, como o sensoriamento remoto e o SIG, se torna imprescindível na gestão das cidades médias.

A eficácia da aplicação do sensoriamento remoto e do SIG é demonstrada em alguns estudos, como a pesquisa de Estevam (2006) que 
apresentou uma metodologia de classificação de favelas na cidade de São José dos Campos, a partir de imagens Ikonos. Nesse estudo, a autora classificou visualmente os objetos urbanos no interior de uma favela, para tal usou o software ecognition. O uso desse software se fez necessário devido à dificuldade em classificar o uso do solo da favela pela cor dos objetos, por isso o ecognition foi uma alternativa para realizar a identificação dos elementos pela sua forma.

Outro trabalho que trata especificamente do uso do sensoriamento remoto no mapeamento de favelas em cidade média foi desenvolvido por Matias e Nascimento (2006), que teve como estudo de caso a cidade de Ponta Grossa (PR). Nessa pesquisa, os autores constataram um número significativo de favelas, 117 aglomerados, que correspondem a uma área representativa do espaço urbano. A partir de imagens do satélite Ikonos foi possível identificar as áreas e estimar a população das favelas localizadas.

Esses trabalhos representam uma amostra da possibilidade de coletar informações de forma rápida e com precisão satisfatória, por isso esses resultados compensam o custo na aquisição da imagem orbital. Antes dos sensores orbitais de alta resolução, o mapeamento de assentamentos urbanos informais era realizado de forma rudimentar com a visita a campo e elaboração de croquis que depois eram reunidos formando um mapa da favela. Com a técnica da aerofotogrametria, o mapeamento do espaço intraurbano avançou, o uso de foto aérea se tornou recomendável para esse tipo de mapeamento, devido à resolução, mesmo quando comparada com as imagens orbitais. A resolução dessas fotografias é maior e melhor, porém quando se avalia custo e praticidade, a imagem de satélite de alta resolução ganha destaque.

Algumas informações importantes das favelas podem ser retiradas das imagens de alta resolução espacial, permitindo definir prioridades para essas áreas. O reconhecimento da incidência de vegetação nessas áreas permite criar planos de arborização, replantio de mata ciliar ou a implantação de áreas verdes. Além disso, a imagem orbital possibilita uma visão geral da área, tornando o plano de urbanização mais eficiente, haja vista que considera toda essa área como um subsistema da malha urbana, ou seja, interligada à cidade, 
o que facilita visualizar essas áreas integradas de forma harmônica com o sistema urbano. O sensoriamento remoto também pode ser usado para analisar a dinâmica interna do território das favelas. Essa tese foi defendida por Panizza (2004) que mostrou que as imagens de satélites de período temporal diferente podem ser usadas como um método para mostrar a dinâmica espacial, pois a imagem representa os elementos materializados no espaço, com isso a sequência temporal de imagem de um mesmo espaço expõe as transformações ocorridas.

O estudo de favelas através da extração de dados das imagens de satélite de alta resolução espacial e a integração desses em um ambiente SIG é uma alternativa para conhecer a realidade socioambiental dessas áreas, bem como para propor medidas de controle de sua expansão nas cidades. As pesquisas de aplicação do sensoriamento remoto e do SIG no espaço da favela encontram dificuldades na aquisição de dados e de materiais para executar essa análise. A necessidade de imagem de alta resolução neste tipo de estudo faz com que o custo desse produto seja um entrave, além disso, a falta de dados socioeconômicos sobre as favelas acentua os obstáculos para esse tipo de pesquisa.

\section{Procedimentos metodológicos}

A metodologia desta pesquisa se mostrou eficaz, tendo em vista que a extração dos dados a partir das imagens de satélites foi satisfatória. Os dados do sensoriamento remoto e as informações vetoriais integrados no SIG permitiram analisar espacialmente as favelas, bem como sua interação com o restante do sistema urbano.

Para identificação do objeto de interesse deste trabalho, a favela, foram usadas técnicas de interpretação aplicadas à imagem de satélite Quick Bird, com resolução espacial de 0,61 metros. Esse método foi útil para localizar área no perímetro urbano de Montes Claros que não apresentou regularidade no formato das ruas e falta de padrão nas quadras. Essas características indicaram áreas com potencial para serem classificadas como favelas, haja vista que estas são ocupações ilegais e não obedecem as leis de parcelamento do solo, logo, apresentam características diferentes dos loteamentos, mesmo aqueles irregulares. 
Depois desse levantamento pela fotointerpretação, foi necessário realizar uma incursão histórica sobre as áreas encontradas para identificar a origem da ocupação, bem como para verificar o proprietário primário desses terrenos. Na sequência, a pesquisa documental na Divisão de Habitação da Secretaria de Políticas Sociais e na unidade do IBGE de Montes Claros permitiu, por fim, identificar as áreas que foram ocupadas ilegalmente. Na Prefeitura Municipal foram analisadas as plantas dos loteamentos, em que as ocupações irregulares se encontravam. Neste momento foi possível, também, identificar a propriedade do terreno na época do parcelamento do solo urbano. No IBGE o levantamento foi feito através da consulta aos setores censitários de 2000 , classificados como aglomerados subnormais.

$\mathrm{Na}$ fase de mapeamento hipsométrico e declividade do perímetro urbano de Montes Claros, o trabalho foi facilitado, devido à existência dos dados em formato digital com boa qualidade e precisão. Esses dados encontrados na Secretaria Municipal de Planejamento foram gerados a partir da digitalização de 71 pranchas do levantamento semicadastral realizado pela empresa de topografia AeroSul S.A, em 1990. As pranchas estão em uma escala de 1:2000, em que as curvas de nível apresentam equidistância de 0,5 metros.

As pranchas digitalizadas foram georreferenciadas no sistema de projeção UTM, fuso 23, com datum de referência o SAD 69, tendo assim um arquivo raster de saída no formato Tiff. Em seguida, esse arquivo serviu de base para a vetorização das isolinhas no software Auto CAD Map 2000 com zoom de 1/5. Na sequência, as linhas vetorizadas receberam os seus respectivos valores altimétricos.

Para executar a modelagem numérica do terreno (MNT), os arquivos shape das curvas de nível e dos pontos cotados foram trabalhados no software SPRING. Depois de avaliada a precisão das isolinhas e dos pontos, geraram-se as grades retangular e triangular.

A geração das grades foi o ponto primário para realizar o trabalho de modelagem numérica, conforme apresentado na figura 01; com essa metodologia realizou-se o mapeamento hipsométrico e clinográfico da cidade de Montes Claros. 


\section{PROCEDIMENTO DA MODELAGEM NUMERICA}

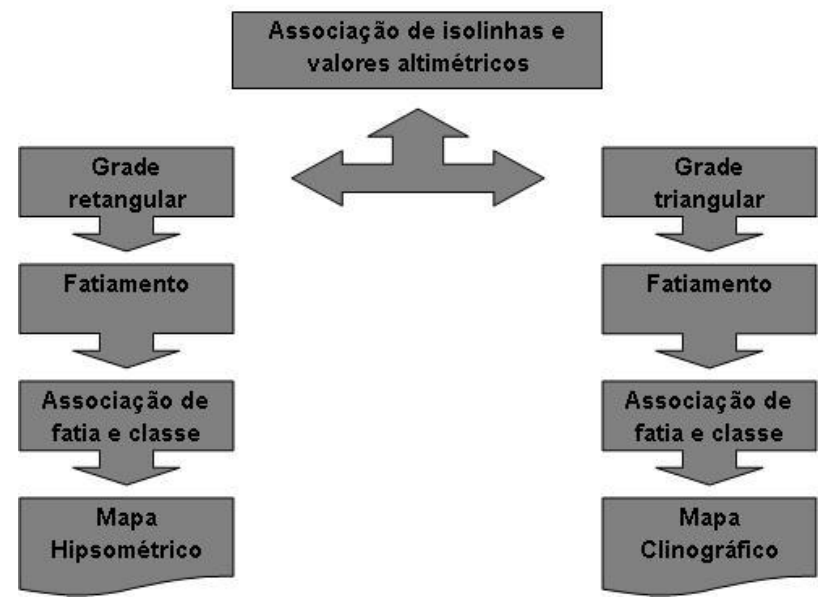

Figura 01 - Etapas para gerar mapas hipsométrico e clinográfico Org.: Leite, M. E., 2008.

Com essa análise, foram definidas cinco classes altimétricas, adotando a opção de fatiamento no software SPRING com o passo variável. Depois que o software executou o comando, as fatias foram associadas às classes, gerando assim o mapa hipsométrico. Para o mapa de declividade o procedimento é semelhante ao do mapa hipsométrico, entretanto a etapa se iniciou com a grade triangular que, depois de definidos os parâmetros da declividade, passou por processo de fatiamento. Nesse momento, foram estabelecidas as classes de declividade em porcentagem e, após processada a imagem com a declividade em porcentagem, as fatias foram agregadas às classes definidas previamente no modelo de dados do SPRING. Em seguida, esses arquivos foram exportado para o software Arc GIS. A escolha da Arc GIS para a função de edição do mapa final está baseada na qualidade dos elementos cartográficos disponíveis no Layout desse software.

\section{Resultados e discussão}

A cidade de Montes Claros se destaca pela concentração populacional e pela importância econômica no cenário regional. Este município está localizado entre as coordenadas geográficas $16^{\circ} 04^{\prime} 57^{\prime \prime}$ e $17^{\circ} 08^{\prime} 41^{\prime \prime}$ de Latitude sul e entre as Longitudes $43^{\circ} 41^{\prime} 56^{\prime \prime}$ e $44^{\circ} 13^{\prime}$ 1" oeste de Greenwich, conforme mapa 01. A mesorregião Norte de Minas Gerais, onde Montes Claros está inserida se caracterizada pelo baixo dinamismo econômico e a precariedade dos indicadores sociais. Com isso, a cidade em estudo se torna o centro para a convergência de pessoas e capital. 


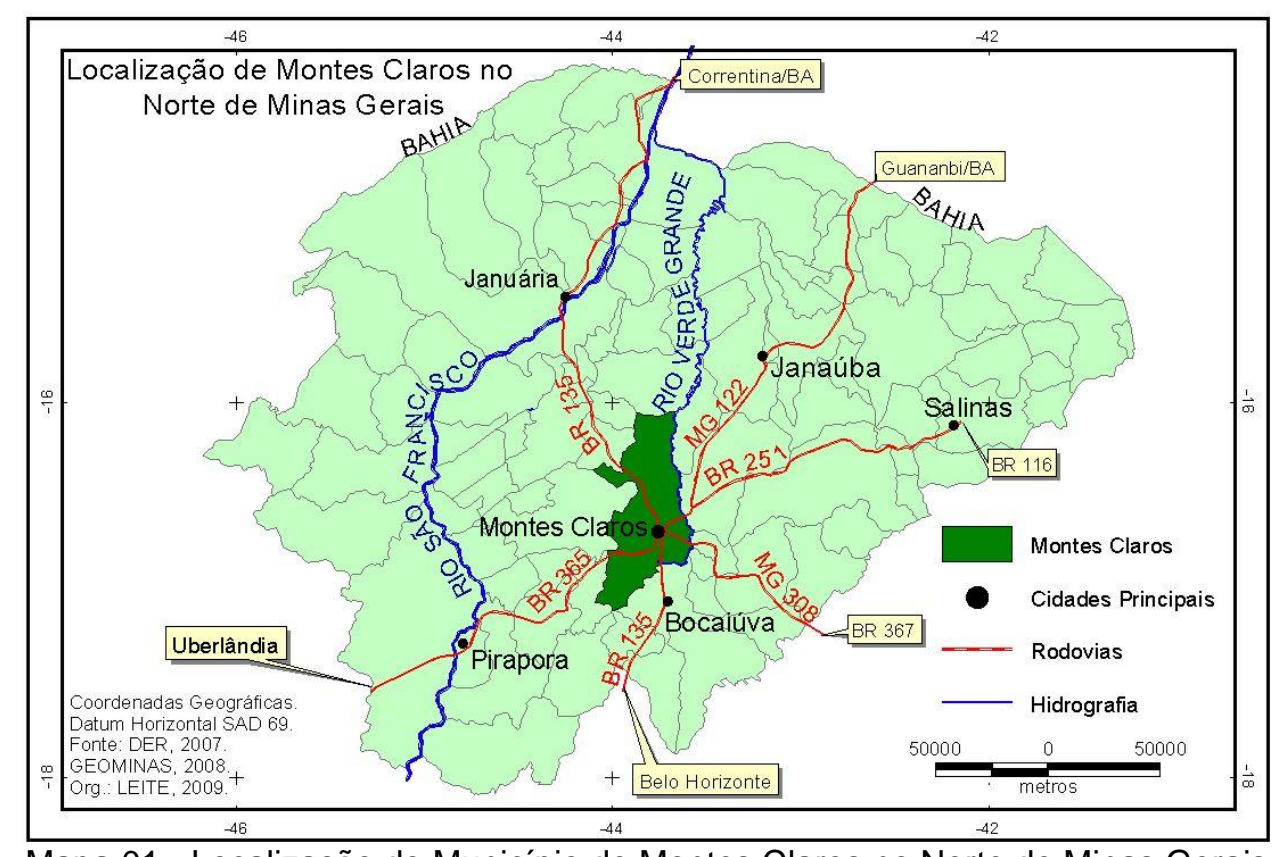

Mapa 01 - Localização do Município de Montes Claros no Norte de Minas Gerais

Para discutir a gênese das favelas de Montes Claros é importante retornar aos dados do crescimento populacional de Montes Claros, haja vista que, entre as décadas de 1960 e 1970, ocorreu um fenômeno demográfico, no qual a população rural se deslocou, em grande parte, para a cidade. Nesse período a população rural de Montes Claros reduziu-se em $274 \%$, enquanto que a população urbana aumentou 183\%. O crescimento da população urbana manteve o mesmo ritmo na década seguinte, totalizando, entre 1970 e 1980, um aumento de $182 \%$ na quantidade de pessoas morando na área urbana de Montes Claros.

Esse rápido crescimento demográfico provocou uma expansão física da cidade na mesma proporção, o que dificultou a adoção de medidas estruturais e sociais para receber os imigrantes. Essa situação culminou na formação de novos espaços que não dispunham de infraestrutura básica, além de comprometer a qualidade das áreas existentes, pois a estrutura existente não era capaz de atender a nova população da cidade.

Esse contexto merece ser analisado numa perspectiva crítica, pois o indutor dessa migração intensa para Montes Claros foi o Estado que inseriu o Norte de Minas na área da SUDENE. Nesse momento, implantou o distrito industrial que recebeu 15 novas fábricas. A industrialização em uma região que 
apresenta baixo dinamismo econômico e indicadores sociais insatisfatórios provocou a migração da população para a cidade de Montes Claros. Diante disso, medidas preventivas para manter a população na zona rural e para criar condições satisfatórias para receber o fluxo migratório que se deslocou para a cidade teriam de estar associadas ao plano de industrialização.

A migração para Montes Claros criou mais um atrativo para as indústrias, a oferta abundante de mão de obra que, diante do contingente disponível, se tornou mais barata. Esses trabalhadores apresentavam um perfil produtivo que interessava apenas à indústria, pois eram pessoas com pequeno nível de instrução. Embora a quantidade de indústrias instaladas fosse significativa, a disponibilidade de trabalhadores era maior, implicando em um elevado número de desempregados. A migração inflacionou o mercado imobiliário urbano de Montes Claros, com isso, a realidade socioeconômica da maior parte dos imigrantes não permitiu a compra ou mesmo o aluguel de moradia, esse cenário provocou o surgimento de novas favelas.

Esse foi o cenário para o processo de favelização ocorrido em Montes Claros entre as décadas de 1970 e 1980 . Entretanto, há de se destacar que existiam favelas antes da industrialização subvencionada pelo Estado. $O$ fato de Montes Claros se destacar como polo urbano desde o início do século XIX fez com que houvesse um fluxo migratório para essa cidade, o que gerou a formação de áreas de ocupação ilegal, como as favelas.

A primeira favela de Montes Claros surge no contexto das transformações políticas ocorridas no Brasil na década de 1930. Nesse momento aconteceram mudanças na legislação trabalhista, na qual foram conferidos maiores direitos aos trabalhadores rurais, esse fator fez com que os produtores rurais demitissem parcela significativa de seus empregados. Essa situação forçou grande parte dos trabalhadores rurais do Norte de Minas Gerais desempregados a se deslocarem para Montes Claros.

Associado ao fator político soma-se o clima semiárido da região que dificulta a produção agrícola, pois apresenta distribuição irregular da chuva, além das altas amplitudes térmicas anuais. Esses fatores integrados provocaram evasão da zona rural e o direcionamento desse fluxo para a cidade 
de Montes Claros na década de 1930, período de formação da primeira favela. Através desta pesquisa, constatou-se que a favela mais antiga de Montes Claros é a favela dos Morrinhos, pois está localizada no morro Dona Germana, com sua ocupação iniciada no ano de 1936.

Depois da Favela dos Morrinhos surgiram, na sequência cronológica, outras duas favelas, a Favela Cidade Cristo Rei e a Favela da Vila Tupã que se formaram nas décadas de 1950 e 1960, respectivamente. Analisando a distribuição dessas primeiras favelas, através do mapa 02, percebe-se que elas estão localizadas, atualmente, próximas à área central da cidade. Entretanto, no período em que surgiram, a malha urbana de Montes Claros se resumia ao que hoje se considera como centro comercial. Dessa forma, quando se formaram, a área de localização era considerada como periferia da cidade.

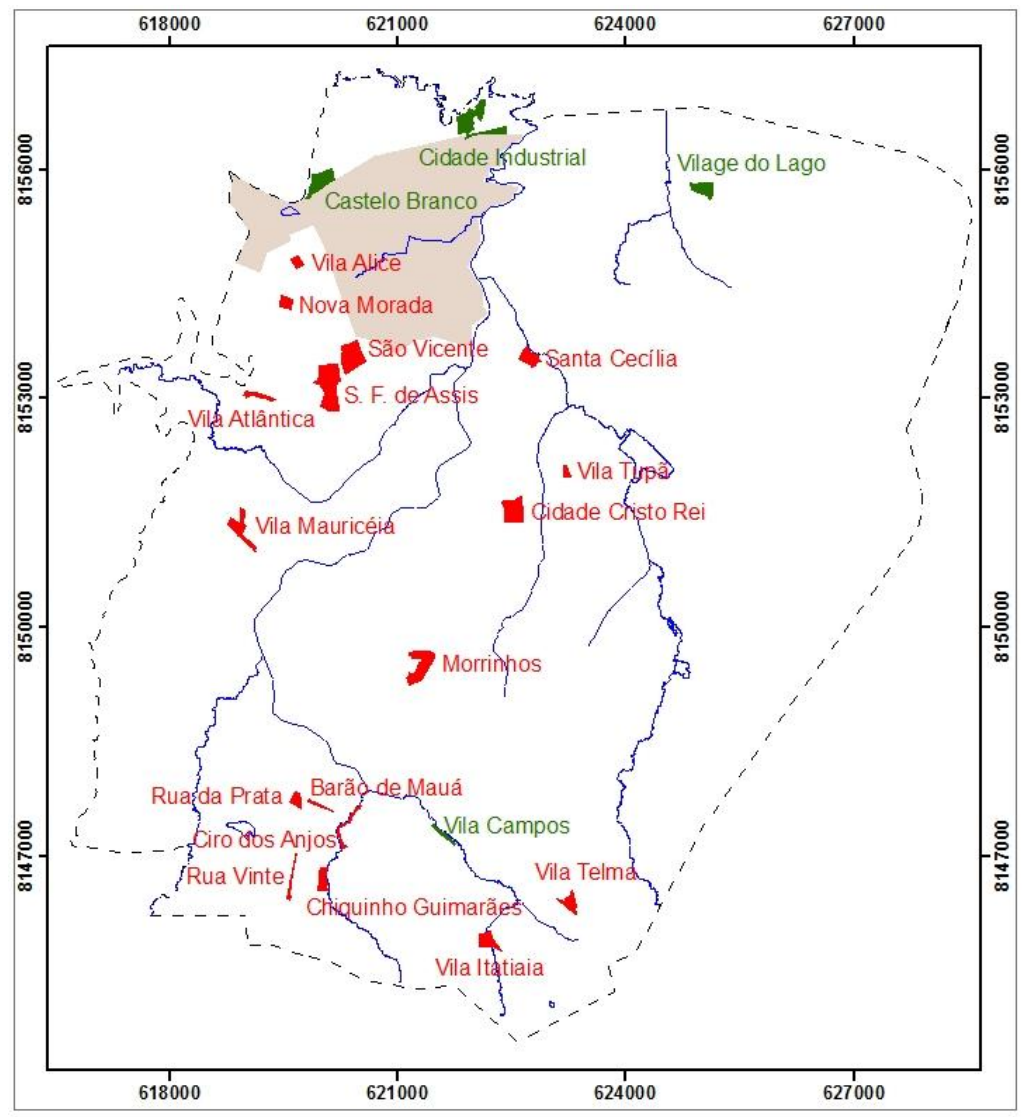

Favelas de Montes Claros/ 2005

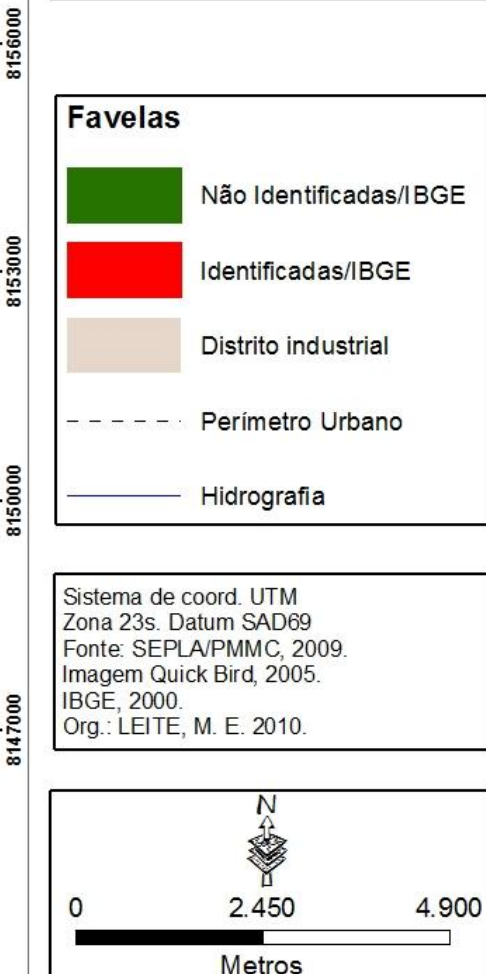

Mapa 02 - Favelas de Montes Claros.

Essa explanação sobre as primeiras favelas de Montes Claros é importante para mostrar que a lógica mercadológica que atua na distribuição espacial das favelas se mantém desde o início desse tipo de moradia na 
cidade. Com a industrialização e a valorização da terra urbana, em virtude da maior procura por imóveis, essa lógica mercadológica se torna mais severa. Isso implicou na exclusão da população pobre para as áreas mais distantes, consequentemente as favelas que proliferaram, após a industrialização subsidiada, surgiram no limite da área urbana.

Analisando a distribuição espacial das favelas de Montes Claros, a partir da ordem temporal de formação, exposta no mapa 03, constatou-se que a distância do centro da cidade, no momento de sua origem, é uma característica comum às favelas, mesmo porque a área urbana era menor, com isso, as favelas mais recentes estão próximas à franja urbana, enquanto que as mais antigas estão mais perto do centro. Os dados representados no mapa 03 confirmam a década de 1970 como o marco cronológico do início do processo de favelização de Montes Claros. Nas décadas de 1970 e 1980 surgiram 14 novas favelas, sendo sete em cada década. Atualmente há, no espaço urbano de Montes Claros, 21 favelas, sendo que, dessas, apenas quatro se formaram entre 1990 e 2005. Com isso, $66,6 \%$ das favelas dessa cidade se originaram nas décadas de 1970 e 1980.

O intenso fluxo migratório para Montes Claros, a partir da década de 1970, foi o fator decisivo para a propagação da ocupação ilegal. Todavia, temse que considerar a conivência e ineficiência do poder público para controlar a expansão das favelas. Os interesses eleitoreiros dos administradores urbanos impediram ações de fiscalização para controlar as invasões. Nesse contexto, Carvalho (2001) afirma que o poder de polícia é negligenciado pelo poder público que permite invasões ou desrespeito às leis de parcelamento do solo, o que traz consequências socioambientais para a cidade e, principalmente, para as áreas ocupadas ilegalmente. 


\section{Cronologia de formação das favelas de Montes Claros}

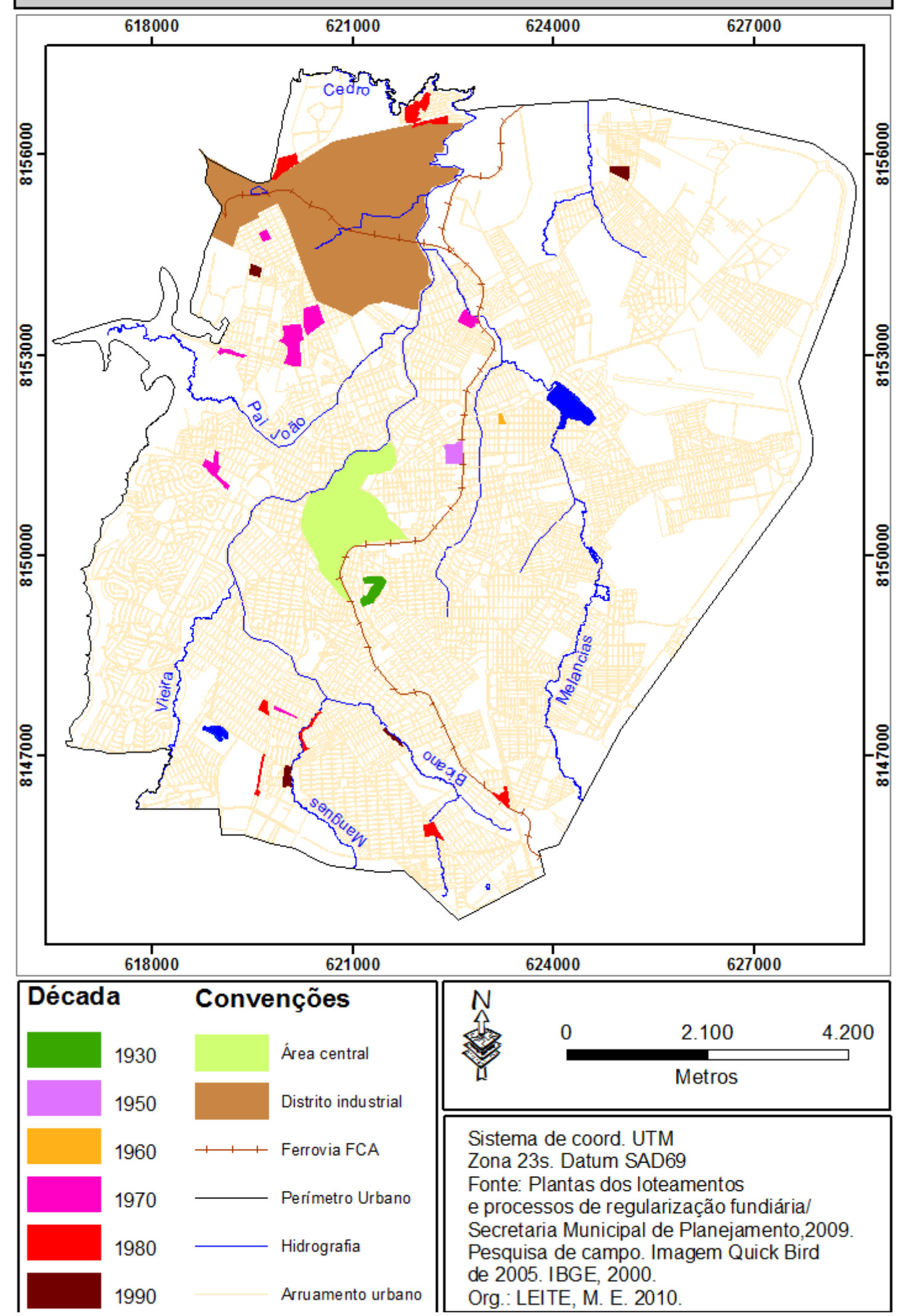

Mapa 03 - Cronologia de formação das favelas de Montes Claros 
A intensidade da migração para Montes Claros foi outro agravante no processo de gestão da cidade, haja vista que a formação constante de novas áreas ilegais dificulta a adoção de políticas públicas para a fiscalização da ocupação do solo, bem como para a criação de alternativas de moradias legalizadas. E, seguindo a tendência, as favelas que surgiram a partir do processo de industrialização concentram-se na periferia. Com base no mapa 03, pode-se perceber que a parte mais ao norte da cidade de Montes Claros se destaca com grande quantidade de favelas. Nessa área estão localizadas oito favelas, sendo elas: Vilage do Lago, Cidade Industrial, Castelo Branco, Vila Alice, Vila São Francisco de Assis, São Vicente, Nova Morada e Vila Atlântica. Essa concentração de favelas nesse local da cidade ocorre pela presença do distrito industrial nessa área, logicamente, influenciado também pela oferta de terra urbana à margem do mercado imobiliário formal. A chegada das primeiras indústrias no distrito industrial foi acompanhada pela ocupação ilegal nas áreas próximas, o que facilitava o acesso dos moradores às indústrias.

O número de favelas na parte sul de Montes Claros também se destaca, uma vez que existem oito favelas. As favelas (Barão de Mauá, Chiquinho Guimarães, Ciro dos Anjos, da Prata, Rua Vinte, Vila Campos, Vila Itatiaia e Vila Telma) têm sua origem ligada a sua posição geográfica, pois estão localizadas na parte sul da cidade, com isso estão próximas a duas rodovias federais, BR-135 e BR-365, que interligam Montes Claros a várias pequenas cidades e localidades rurais. A proximidade e acessibilidade facilitaram a migração de pessoas de áreas próximas a se fixarem na parte sul da cidade. Além disso, até a década de 1990, essa região apresentava pequena valorização comercial. Dessa forma, o baixo preço da terra urbana, nessa área, não despertava interesse do mercado imobiliário legal.

$\mathrm{Na}$ área entre o centro e o oeste do perímetro urbano encontram-se cinco favelas, Morrinhos, Cidade Cristo Rei, Vila Tupã, Vila Mauricéia e Santa Cecília. Essas favelas são as mais próximas ao centro comercial de Montes Claros e estão em área de maior valorização imobiliária, isso ocorre pois são as mais antigas da cidade, logo, a área urbana, no período de formação das favelas, apresentava configuração diferente da atual. 
A análise sobre a espacialização das favelas mostrou que existe padrão na sua distribuição. Como apresentado, a posição geográfica é determinante, pois a presença de elementos de atração populacional, como a proximidade com indústrias e rodovias, fez com que as favelas se polarizassem nas zonas norte e sul da cidade. Além da posição geográfica, pode-se constatar nesta pesquisa que a propriedade do terreno é outro ponto a ser considerado na sua formação.

Os dados do quadro 01 mostram que, das vinte e uma favelas existentes, dez surgiram em terrenos públicos, isto representa $48 \%$ do total. Essa situação tem relação com a não ocupação das áreas destinadas ao uso institucional e áreas verdes, pois, como esses espaços permanecem vagos, a população de baixa renda, sem acesso à moradia legal, as ocupa.

Quadro 01 - Assentamentos ilegais da cidade de Montes Claros

\begin{tabular}{|l|l|l|}
\hline Favelas & Origem & Propriedade \\
\hline 1. Morrinhos & 1930 & Igreja Católica \\
\hline 2. Cidade Cristo Rei & 1950 & Igreja Católica \\
\hline 3. Vila Tupã & 1960 & Particular \\
\hline 4. Barão de Mauá & 1970 & Particular \\
\hline 5. Santa Cecília & 1970 & Público/Prefeitura \\
\hline 6. São Vicente & 1970 & Igreja Católica \\
\hline 7. Vila Alice & 1970 & Igreja Católica \\
\hline 8. Vila Atlântica & 1970 & Particular \\
\hline 9. Vila Mauricéia & 1970 & CEMIG \\
\hline 10. Vila São Franc. de Assis & 1970 & Igreja Católica \\
\hline 11. Castelo Branco & 1980 & CEMIG \\
\hline 12. Cidade Industrial & 1980 & CEMIG \\
\hline 13. Ciro dos Anjos & 1980 & Público/Prefeitura \\
\hline 14. Da Prata & 1980 & Público/Prefeitura \\
\hline 15. Rua Vinte & 1980 & Público/DER \\
\hline 16. Vila Itatiaia & 1980 & Público/Prefeitura \\
\hline 17. Vila Telma & 1980 & Público/Prefeitura \\
\hline 18. Chiquinho Guimarães & 1990 & Público/Prefeitura/pública \\
\hline 19. Nova Morada & 1990 & Público/Prefeitura \\
\hline 20. Vila Campos & 1990 & Público/Prefeitura \\
\hline 21. Vilage do Lago & 1990 & Público/Prefeitura \\
\hline
\end{tabular}

Fonte: Plantas dos loteamentos urbanos/SEPLA/PMMC. Pesquisa de campo, 2009

Essa informação expõe o problema da gestão do espaço urbano, pois é função do poder público controlar a forma de expansão da cidade. Por isso, a aprovação dos loteamentos passa pela análise do município. Nesse momento, deve-se verificar o percentual de área previsto em lei destinado ao uso 
institucional e às áreas verdes, além de planejar os serviços urbanos que serão instalados nesse local. O terreno público que fica desocupado é ponto potencial para invasão e formação de favela, pois envolve, nesse contexto de retirada dos ocupantes, interesses políticos, além de entraves burocráticos, implicando, também, em custos para o município.

A formação de favelas em imóveis pertencentes à Igreja Católica também chama atenção, uma vez que existem cinco favelas nessa condição, o que, de acordo com o gráfico 01 , representa $24 \%$ da quantidade total de favelas. Essas favelas se caracterizam por estarem entre as mais antigas. Além da ocupação em áreas públicas e pertencentes à Igreja Católica, existem três favelas, em Montes Claros, que se formaram em áreas non aedificandi da Companhia Energética de Minas Gerais - CEMIG. Neste último caso, o espaço sob a linha de transmissão de energia elétrica foi invadido, o que faz dessa ocupação uma área de risco. Diante desse levantamento sobre a propriedade da área ocupada, nota-se que apenas três terrenos eram de propriedade particular.

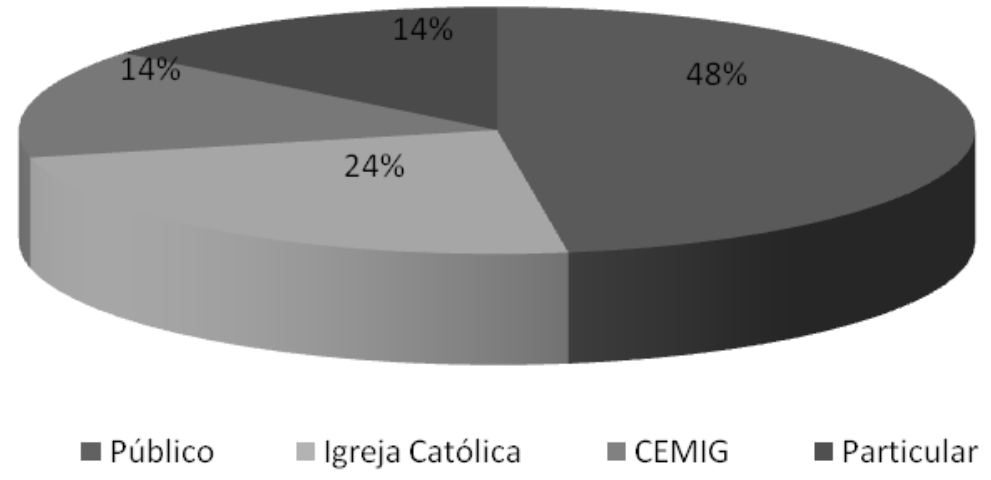

Gráfico 01 - Propriedade dos terrenos das favelas de Montes Claros

É necessário entender que a sociedade urbana entende a favela como um vizinho indesejável, que traz a violência. Além disso, a favela contraria a ideia do direito à propriedade privada, ou seja, a sociedade transfere a responsabilidade da desordem social para a favela. Devido a essa representação que a sociedade faz da favela, torna-se interessante para os detentores de capital, promotores imobiliários e o Estado isolar a favela, permitindo apenas seu surgimento na periferia desprovida de infraestrutura e distante das áreas nobres. 
Pode-se perceber a manifestação dos interesses desses agentes nos espaços urbanos ao verificar que a maior parte das áreas invadidas tem declividade acentuada, como os morros, ou estão às margens de córregos, onde são despejados esgotos domésticos e industriais, ambas as áreas estão na periferia pobre. Essa tendência pode ser explicada pela lógica mercadológica do solo urbano, na qual essas características citadas tendem a reduzir o valor do solo urbano, sendo assim, a pressão sobre as pessoas que invadem esse tipo de terreno é menor se comparada às invasões em áreas planas e bem localizadas, cujo valor da terra é maior.

Ao analisar o mapa 04, com a hipsometria e a distribuição das favelas, ratifica-se a ideia apresentada no parágrafo anterior. A topografia da cidade varia entre 585 a 940 metros de altitude. No entanto, a maior parte do perímetro urbano tem uma variação de apenas 60 metros, uma vez que as classes de 610 a 670 metros ocupam $78 \mathrm{~km}^{2}$ do espaço urbano, isto representa $78 \%$ da área do perímetro urbano. Na parte norte da cidade, sobretudo na noroeste está o relevo mais elevado, entre 690 e 940 metros de altitude, que compreende a Serra do Ibituruna, assim como no extremo sul. A área com as menores altitudes do relevo, inferior a 610 metros, fica localizada a norte, na foz do rio Cedro, na confluência com o rio Viera.

Nessa estrutura, as favelas se encontram distribuídas em espaços com agravantes ambientais, como a proximidade de cursos da água ou em áreas com declividade elevada no contexto do relevo urbano. No primeiro caso, há maior incidência de favelas, sobretudo na zona sul da cidade, como expõe o mapa 04. Nesse caso, a favela se forma em área de preservação permanente, suprimindo a vegetação ripária, além disso, o despejo de esgoto doméstico e de lixo no curso da água que está próximo potencializa a degradação ambiental. Esses impactos aumentam a possibilidade de enchentes na favela, o que traz perdas materiais para os moradores, bem como coloca em risco a saúde da população desse tipo de moradia. 


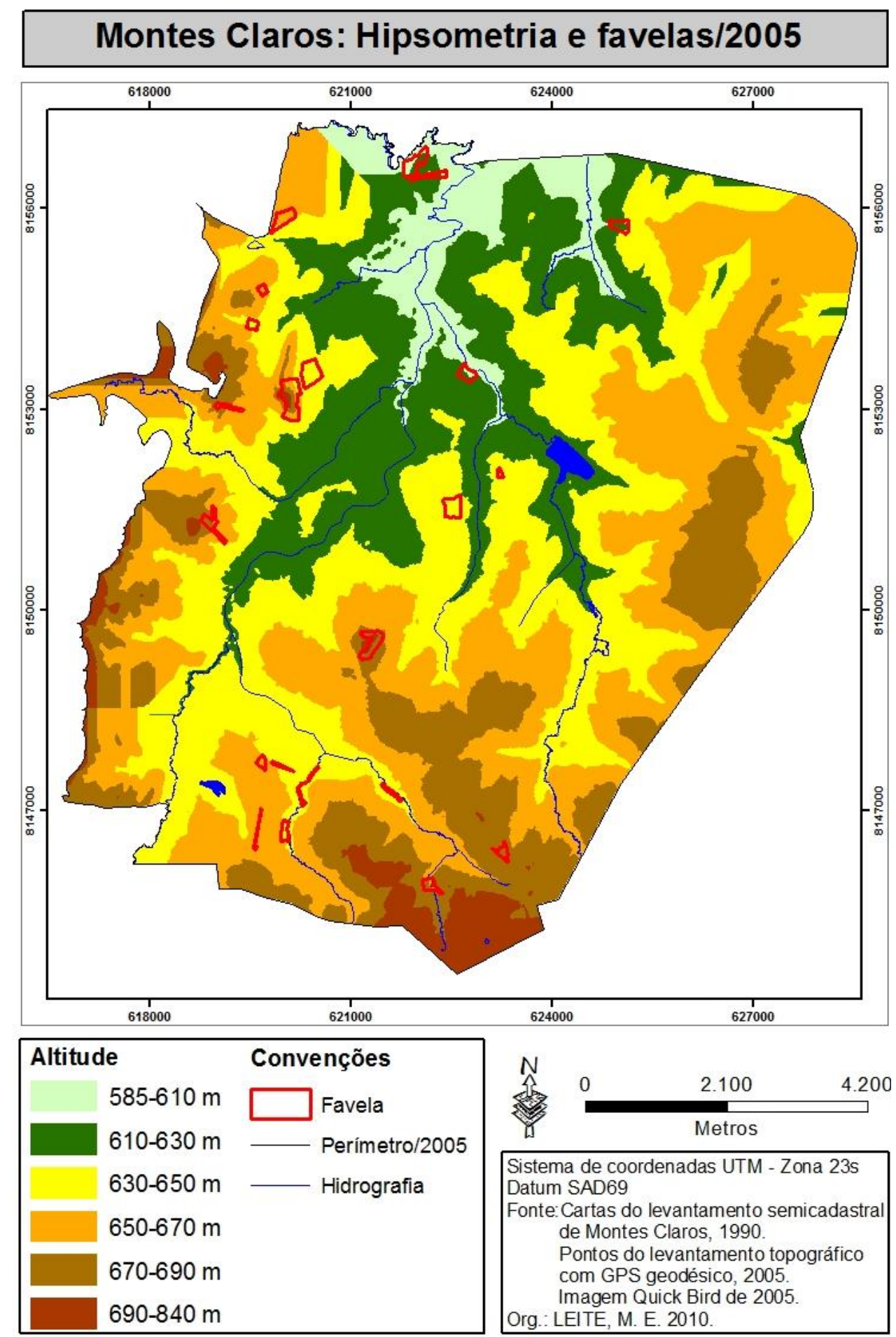

Mapa 04 - Montes Claros: Hipsometria e favelas

Com relação às favelas localizadas em áreas com declividade acentuada, constatou-se, de maneira geral, através do mapa 05, que o relevo da cidade de Montes Claros é plano, predominando espaços com declividade inferior a 5\%. As áreas com declividade elevada estão próximas aos cursos da 
água presentes no perímetro urbano. Esse atributo agrava a situação de risco de desastre ambiental nas favelas, uma vez que é alta a quantidade de assentamentos precários nas margens dos rios, principalmente na parte sul da cidade.

A constatação de favela em área com relevo íngreme e próximo a curso da água deve ser associada a outras características da cidade, como o clima, que se destaca por chuvas concentradas com alto índice pluviométrico mensal, como mostrado no gráfico 02 com o climograma da cidade de Montes Claros.

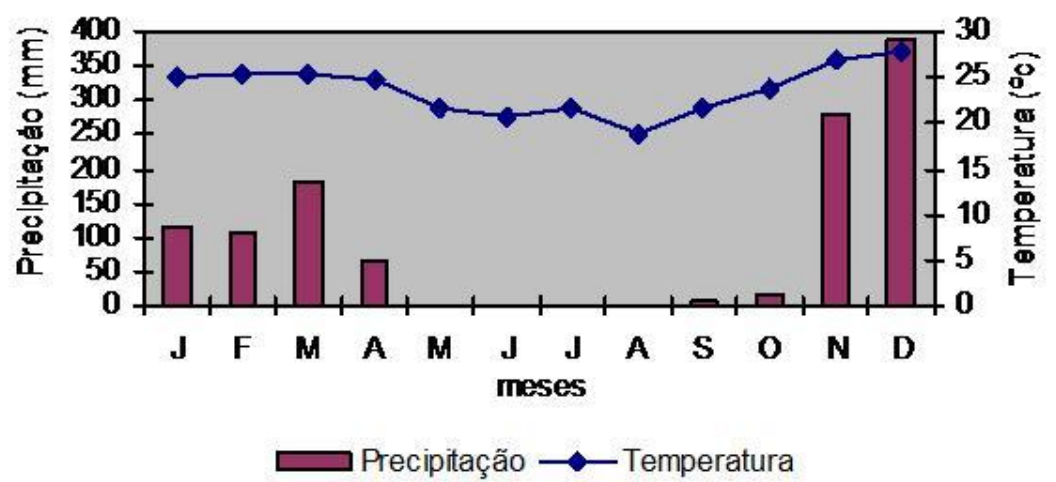

Gráfico 02 - Climograma da cidade de Montes Claros, 2008

Fonte: UNIMONTES, 2008. Org.: Leite, M. E. 2009.

Essa situação ambiental descrita atrelada à realidade social dos aglomerados ilegais torna o cenário mais vulnerável à ocorrência de desastres como enchentes e deslizamento de encostas e barrancos. A figura 02 mostra uma situação comum em algumas favelas de Montes Claros, a ocupação de terreno próximo a talude.

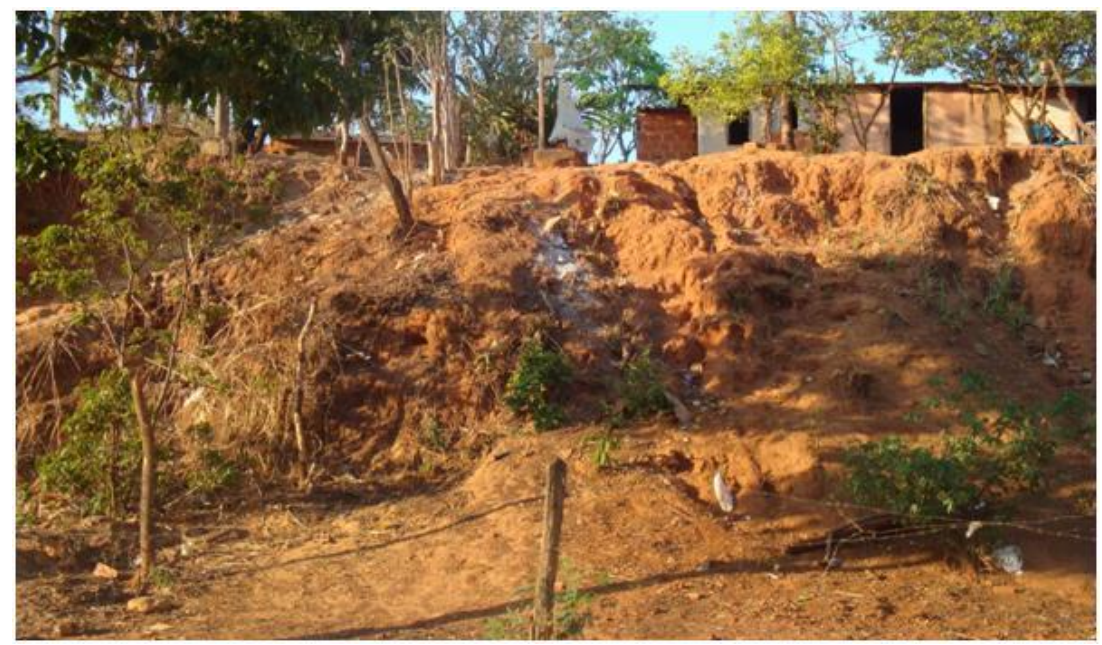

Figura 02 - Ocupação de terreno próximo a talude na Vila Atlântica Autor: Leite, 2010. 


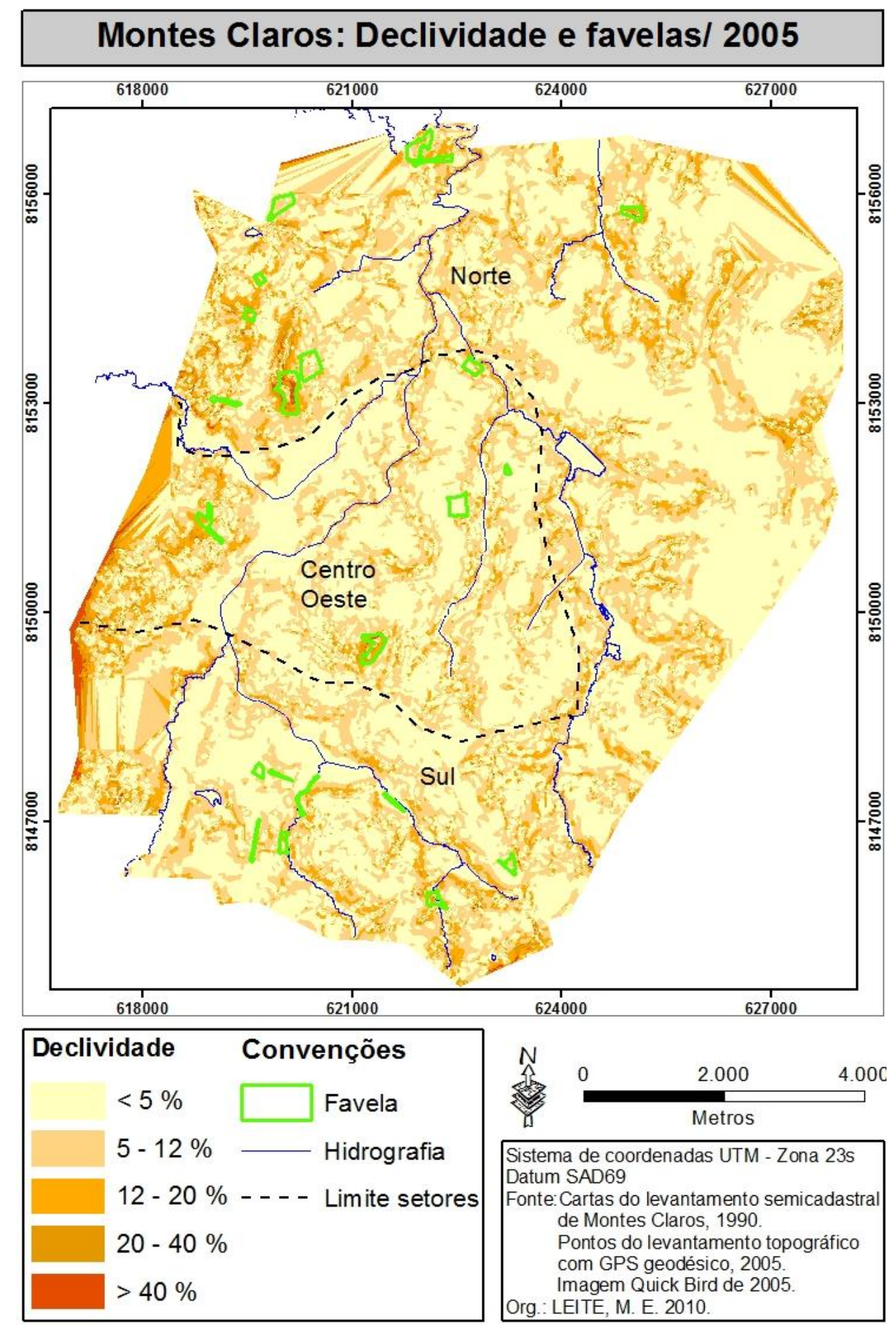

Mapa 05 - Montes Claros: Declividade e favelas

As áreas de declividade acima de $12 \%$ estão concentradas na parte norte da cidade, de acordo com o mapa 05. Essa área se destaca por apresentar sete favelas. A figura 03 mostra uma dessas favelas, a Vila São Francisco de Assis, que apresenta ocupação da encosta do Morro do Frade. 
Além das ocupações ilegais do noroeste, as favelas do Vilage do Lago, no nordeste da cidade, Morrinhos e Vila Mauricéia, na zona centro-oeste, estão em áreas com alta declividade.

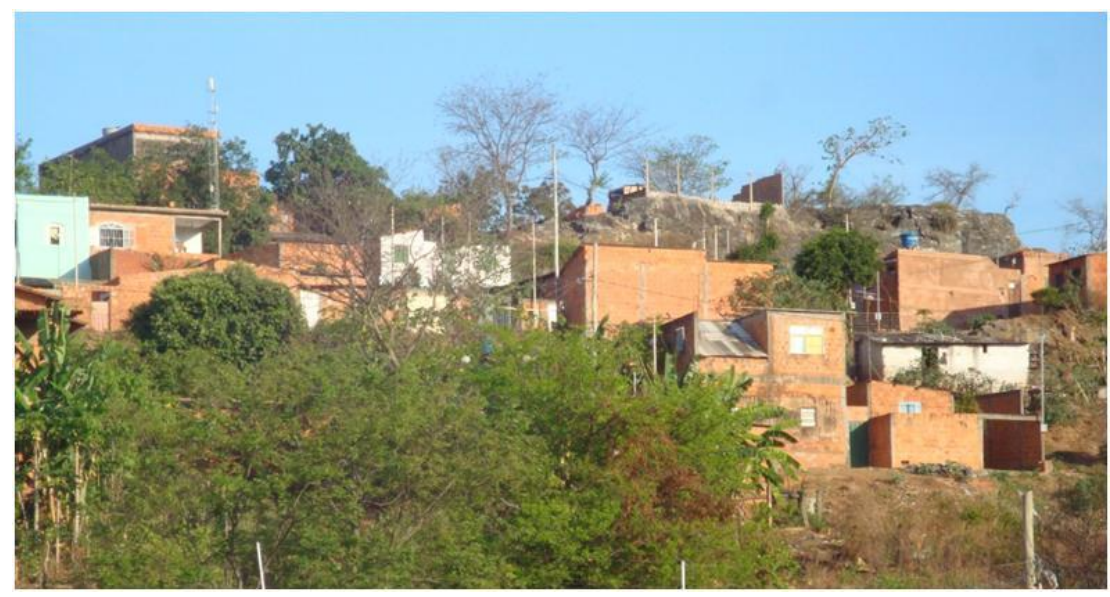

Figura 03 - Construções na encosta do Morro do Frade, na Vila São Francisco de Assis

Autor: Leite, 2010.

Já as favelas em terreno com declividade inferior a 5\% são minoria em Montes Claros, estão nessa situação apenas a Cidade Cristo Rei e Vila Tupã, na parte central, e a favela da Rua da Prata, na zona sul. Essas informações comprovam que as áreas invadidas para moradia de baixa renda apresentam características ambientais específicas, como a declividade acentuada e a proximidade de curso da água, que reduzem o interesse do mercado imobiliário, mas que apresentam riscos à saúde dos moradores que residem nesses espaços.

Portanto, o processo pelo qual uma favela surge não é tão simples como se pode pensar, não é só invadir uma área e construir as casas. Os interessados em ocupar uma área têm que, geralmente, considerar a viabilidade em invadir determinada área, pois além de levar em conta o interesse dos proprietários e do Estado sobre tal área, têm que ponderar os seus próprios interesses.

\section{Considerações finais}

Escolher uma área para ocupar é uma questão difícil para a população pobre, pois é necessário tentar otimizar o custo habitacional, a garantia da 
posse e a qualidade do abrigo. Esse conflito de interesses associado à dinâmica urbana faz com que a favela se materialize em áreas periféricas. A distribuição das favelas da cidade de Montes Claros seguiu a lógica mercadológica do solo urbano do período em que cada favela surgiu, ou seja, todas as favelas da cidade surgiram na periferia pobre, na qual há uma deficiência de infraestrutura urbana.

A carência de infraestrutura associada à condição precária das construções, em que são usados materiais não recomendados para moradia, como madeiras e plásticos, coloca as favelas em uma situação de risco ambiental. Além disso, as características físicas do espaço onde se localiza a favela é um agravante da situação de risco. A proximidade com cursos da água, como mostrados nos mapas, e a característica climática de Montes Claros, em que as chuvas são concentradas no verão, torna real a possibilidade de enchentes. Além disso, as características do relevo, com as favelas ocupando terrenos em áreas de maior declividade, podem levar ao desmoronamento das construções.

Esses resultados apontados demonstram a urgência em pensar a questão habitacional em cidades médias, exemplificado neste trabalho pela cidade de Montes Claros. Esse tipo de cidade apresenta índices de crescimento demográficos elevados, agravando assim o problema da moradia. No entanto, o cenário atual permite uma intervenção estatal para minimizar esses problemas $\mathrm{e}$ as geotecnologias destacam como instrumentos importantes para nortear o planejamento das ações públicas, bem como para auxiliar na gestão dos espaços de moradia de baixa renda.

\section{Referências}

CARVALHO, P. F. de. Problemas Ambientais na produção da cidade e da habitação de interesse social. In: CARVALHO, P. F. de; BRAGA, R. (Org.). Perspectivas de gestão ambiental em cidades médias. Rio Claro: LPMUNESP, 2001.138p. p. 27-37.

ESTEVAM, E. A. Classificação de áreas de favelas a partir de imagens Ikonos: viabilidade de uso de uma abordagem orientada a objetos. $132 \mathrm{p}$. Dissertação (Mestrado em Ciências Cartográficas) - Faculdade de Ciências e Tecnologia/UNESP. Presidente Prudente. 2006. 
GROSTEIN, M. Análise dos processos de ocupação irregular do solo e dos processos de expansão e crescimento das cidades. In: MOTTA, D. M. Gestão do uso do solo e disfunções do crescimento urbano: instrumento de planejamento e gestão urbana em aglomerações urbanas: uma análise comparativa. Brasília: IPEA, 2002. 212p. p.32-36.

IBGE. Enciclopédia dos Municípios Brasileiros. Rio de Janeiro: IBGE, 1960, 1970, 1980, 1991 e 2000.

MATIAS, L. F.; NASCIMENTO, E. do. Geoprocessamento aplicado ao mapeamento das áreas de ocupação irregular na cidade de Ponta Grossa (PR). Revista Geografia. Rio Claro, v. 31, n. 2, p. 317-330, 2006.

PANIZZA, A. C. Imagens orbitais, cartas e coremas: uma proposta metodológica para o estudo da organização e dinâmica espacial. Aplicação ao município de Ubatuba, Litoral Norte, estado de São Paulo/Brasil. 302 p. 2004. Tese (Doutorado em Geografia) - Departamento de Geografia, Faculdade de Filosofia, Letras e Ciências Humanas da Universidade de São Paulo. São Paulo, 2004.

SANTOS, M. Manual de geografia urbana. São Paulo: Hucitec, 1981. 214p.

SOUZA, M. L. de. ABC desenvolvimento urbano. Rio de Janeiro: Bertrand Brasil, 2003. 190p.

UN-HABITAT. United Nations Human Settlements Programme. The challenge of slums: global report on human settlements. New York. 2003. 319p. 